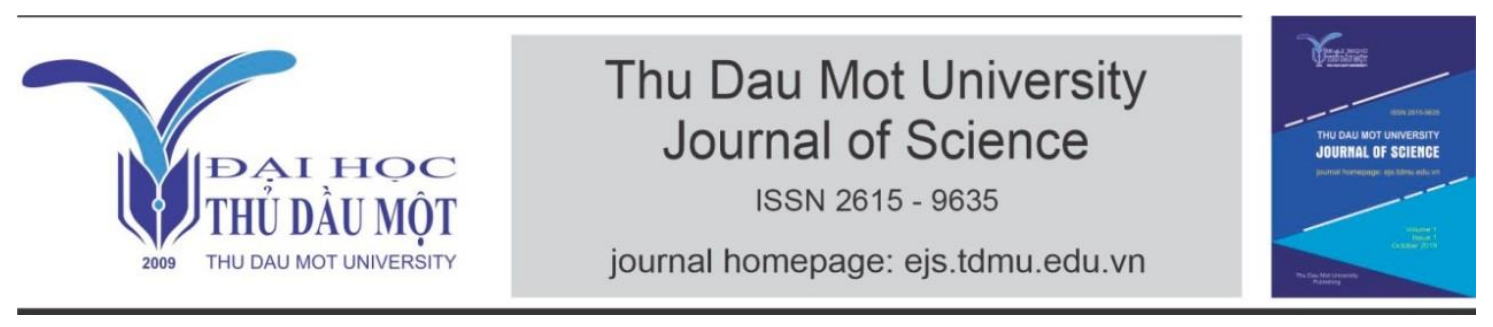

\title{
Innovative Techniques and the Integrated Model of Teaching the First Accounting Course for English as Second Language learners
}

by Mary Precy Aguilar-Lego (United Arab Emirates University (UAEU), Al Ai, UAE)

Article Info: Received Aug. $28^{\text {th }}, 2020$, Accepted Sep. $10^{\text {th }}, 2020$, Available online Sep. $15^{\text {th }}, 2020$ Corresponding author: marylego@uaeu.ac.ae

https://doi.org/10.37550/tdmu.EJS/2020.03.063

\begin{abstract}
Across the world, the first accounting course provides serious challenges for teaching. These arise from powerful negative perceptions which include the anxiety associated with tertiary-level study and the differing backgrounds or majors of students required to take the course. This paper outlines some examples of nontraditional teaching techniques and highlights how the course could be best structured to overcome such negative views while at the same time responding to the changes in the industry. The design and content of the proposed course emphasizes the USER approach and is directed to English as second language learners. This is a case study in an Australian offshore campus and is the end result of the progressive improvement in the structure and delivery of the course.
\end{abstract}

Keywords: accounting education, teaching introductory accounting, first year higher education, branch campus teaching

\section{Introduction}

There have been considerable changes in the role of accounting in the success of businesses. Employers expect accounting graduates to have well-rounded knowledge 
about issues confronting business, solve problems and make sound decisions. Accounting professionals should also display a high degree of teamwork and leadership skills, excellent interpersonal and communication skills, behave ethically as well as be equipped with real-world experience (Abbott \& Palatnik, 2018; Camp \& Schnaderm 2010; Jackling \& De Lange, 2009; Kavanagh \& Drennan, 2008). Recognising, these changed expectations, accounting education has to adapt and improve in order to meet the demands of industry and prepare students to be workplace ready.

There have been significant efforts to improve accounting education since 1989 brought about by the linkages between the professional organisation of accounting academics and industry. This has resulted to the creation of the Accounting Education Change Commission (AECC) in the US which had a significant impact on accounting education. AECC was formed in 1989 "as a catalyst for improving the academic preparation of accountants so that entrants to the accounting profession possess the skills, knowledge, and attitudes required for success in accounting paths" (AECC, 1990). Since then, numerous schemes have been implemented to change accounting education in response to the needs of industry. Despite these many efforts, the need for change and improvement in the delivery of accounting courses persists (Abbot \& Palatnik, 2018; Black 2012; Bonner, 2012; Madsen, 2015). In the aim of focusing on the needed change, recommendations to improve the accounting curriculum and engage learners were identified. Innovative techniques in the delivery were also encouraged as traditional ways of teaching have been observed in accounting teaching, particularly in the delivery of the first year course (Pathways Commission, 2012).

\section{The first accounting course}

The importance of the first accounting course should not be overlooked. In fact, the first (introductory) accounting serves as the gateway to a business or accounting career (Abbott \& Palatnik, 2018; Pathways Commission, 2012; Spiceland et al., 2015). The structure and teaching of Introductory Accounting poses significant challenges with a variety of issues needing consideration. Students in the course have diverse majors and career objectives (Warren \& Young, 2012) with differing aims and perceptions of the usefulness of Accounting to their future careers. Some students taking the course have low motivation (Turner, Lesseig \& Fulmer, 2006); some have negative perceptions, describing the course as "boring", related to "high-level mathematics", and "difficult", (Mladenovic, 2000, p 136). In addition, those who are majoring in other business courses consider the course to produce "moderate-to-severe anxiety" (Malgwi, 2004, p 81).

Traditionally, the teaching of the course is focused on the technical aspects such as performing debits and credits, recording business transactions and preparing financial reports. The directive from AECC aims to promote the use of financial information as a 
decision making tool or the 'USER' approach, encourage students to be active participants in the learning process rather than as passive receivers of knowledge (Williams, 1993). The emphasis is placed on greater student involvement as a tool for effective learning. This effort has led to changes in the 'user approach' of textbooks and other printed materials (Dresnack, \& Callahan, 2004, p 60). The challenge also lies in exploring the use of innovative methods to achieve the active learning outcome desired. In the literature, such non-traditional teaching approaches include the use of laboratory sessions, computer assignments, simulations, team learning, and supplemental instruction (SI) (Etter, Burmeister \& Elder, 2000) among others.

The traditional approach may have been appropriate in previous years but is not relevant to the present time as there are considerable changes in the workplace due to the fact that employers of CPA's have reinvented themselves as "information consultants" rather than preparers (Albrecht and Sach, 2000). Additionally, the new approach is advantageous to academic institutions and likely to increase the number of students majoring in the field of accounting which in the past had faced declining enrolments. It will also provide non accounting majors taking introductory accounting, of which there are many in business schools, a realisation of the relevance and usefulness of the course (Diller-Haas, 2004).

Extensive studies have been done in the US and Australia on the Introductory Accounting structure and teaching but there has been a lack of emphasis in offshore campuses where most students use English as a second language. If students whose native language is English are facing numerous problems with the course, those who have English as a second language encounter even more obstacles.

\section{Non traditional teaching techniques}

Given the changed expectations, the focus of teaching introductory accounting has been geared towards the 'user approach' for selection of textbooks and other printed materials of the course (Dresnack \& Callahan III, 1998). Lecturers are faced with the challenge of exploring innovative methods to incorporate in their teaching and thereby attain the active learning outcome desired. These changes in turn have led to the different studies on the non traditional teaching approaches. Non traditional in Introductory Accounting teaching focuses on the role of accounting information to users, increased emphasis on the learning process, encouraging active participation from students such as team collaboration (Lighter et al., 2007), heavy integration of other accounting related topics such as tax, managerial accounting, auditing and other areas, and also the integration of technology in the course (Boyd, Boyd and Boyd, 2000; Caldwell et al., 1996; Diller- Haas, 2004; Lighter et al., 2007; Williams, 1993). 
In the study by Saunders et al., (2003), of 106 introductory accounting course chairpersons in the US, the following non traditional teaching models were identified: laboratory sessions, computer assignments, simulations, and team learning. A laboratory session in the US is similar to tutorial sessions in Australian universities. Tutorial sessions are extra hours required for students to attend, do exercises or other extra work in the subject with the guide of a tutor (Biggs, 2003). The students do much of the work, thus they are actively involved. Saunders et al., (2003), argued that as a lab session is not a new initiative, it can still be considered a non traditional method due to the fact that $84.9 \%$ of courses had no such requirement in the teaching of introductory accounting. Based on the research, $54.3 \%$ have been using computer assignments. In addition, $20 \%$ of the respondents required simulations in their introductory accounting classes. Finally, team learning was used in $60.6 \%$ of courses. The study however did not provide detailed information on how these were undertaken, it simply measured whether US schools have responded to the call of improving accounting education and the use of non traditional approaches.

Teams or groupings are highly visible in the workplace. Organizations have explicitly expressed the need for hiring employees who are able to work effectively as a member of a team. In light of this development in the workplace, Introductory Accounting has responded by employing team building activities in teaching. In the study made by Miglietti (2002), a cooperative small group was used as a practical approach to teaching introductory accounting classes. A set of guidelines was established to manage group formation, orientation and evaluation. The instructor was responsible for assigning students to groups of 4 members, keeping the group together for the duration of the semester, and providing related group assignments or tasks accounting to $30-40 \%$ of the course grade. The instructor met with individual groups in order to ensure that roles and responsibilities of each student were clearly communicated and the method of approaching tasks clarified. An evaluation was followed to assess individual's efforts, using a marking scheme or criteria for both individual efforts and as a peer/s. The majority of the marks were controlled by the instructor and a lesser mark was taken from peer evaluations. In the process of this study, 246 students were taken as samples and were assessed based partly on the students' achievement as cooperative member of their group. The study revealed that the approach of using cooperative small groups significantly enhanced students' achievement where in $92 \%$ of students received a grade of A or B in the group assignments submitted to the instructor and $91 \%$ received a grade $\mathrm{B}$ or higher on the peer evaluation.

Similarly Etter et al., (2000), have used the concept of cooperative learning model to improve student performance and retain students in Introductory Accounting. The study used the Supplemental Instruction (SI) model as developed by Deanne Martin during 
the mid 1970s. This SI model is an enhanced cooperative learning technique using out of class study sessions rather than in-class sessions as previously outlined in cooperative small group studied by Miglietti (2002). The SI model had long been used in high failure rate courses and had been known as having high degree of effectiveness retaining and improving students' performance. The SI uses a group of 6-15 students per session. The session meets outside of class for 40 minutes, three times in a week. The session is facilitated by an SI Leader who had successfully completed introductory accounting courses with a GPA of greater than 3.5 and with good interpersonal and communication skills. The supervisors or lecturers train SI leaders and meet them regularly for follow up and evaluation of every session. Activities in the SI session include: activities for revision of past lectures, practice on exercises, informal quizzes and other activities requiring student participation. The most important aspect of SI is the informal social atmosphere it depicts, thus learning is enhanced as the SI leader and students work hand in hand on every structure of the sessions. Descriptive data of the study suggested that SI is an effective tool in improving students' performance and retention in Introductory Accounting.

Another new approach is the use of articles from popular press in the teaching of introductory accounting. This article was prepared by Rankine et al., in 1994. Interesting articles from popular press were used as a tool for in class discussion. The articles were followed by prepared questions for students to 'do systematically and critically analyse'. The right questions should be asked and prepared in advance to stimulate interest and create spontaneous discussions. Articles from popular press would not only realise the 'user' approach requirement in accounting but also equips students with real business environment perspectives. However, the disadvantage of this type of method reveals that students might view the articles as vague and may overlook the accounting issues as the main essence of the article. In addressing this problem, the author suggests that questions formulated should be specific to give students a definite structure to analyse the article.

An empirical study on the integration of an accounting simulation in a form of a game called, "The Accounting Game" into an introductory accounting course was undertaken by Steven in 2000. It specifically focused on comparing students' perceptions and game performance. With the use of a non randomised control group with a pre-test and posttest provided was conducted in four (4) classes of introductory accounting. The experimental group was given an 8 hour accounting simulation and was then compared to the traditional accounting instruction using the same faculty member. A pre-test was undertaken by both groups and both had been required to complete a survey to evaluate the students' perceptions. In addition, a standard examination was set for both groups to measure their course performance. The results show that 'The Accounting Game' is 
effective in improving performance of students in the course and has encouraged significantly positive attitude of students towards accounting.

Another approach is the use of the Internet as a teaching tool in accounting. Rebele et al., (1998) argued that the 'educational technological advances in accounting learning' have made the use of computer based instruction using the Internet made helpful in accounting education (Sangster \& Mulligan, 1997). A study on the strength and weaknesses of an introductory accounting course using the Internet was conducted by Larson-Birney in 2001. A web-based management system was set up and a computer-based instruction was used. The result of the study indicated that these methods of teaching in introductory accounting were effective and easy to use. It showed that eighty seven per cent (87\%) of students in the class indicated interest in this kind of approach. However, students also reported some confusion in the initial stage of the course as the method was unfamiliar to them. The withdrawal rate was also 'three times higher' compared to the normal class. In another study, Carl and Desmore (1988) assessed the effectiveness of using video conferencing in Introductory Accounting as a form of distance education. The method used 'one-way full motion video conferencing' whereby the students were connected to a class and the teacher with the use of a telephone. The study indicated that those who were learning in a distance mode performed better than the in-class students.

Halabi et al., (2005) explored the use of tele-teaching in introductory accounting within a multi-campus university. The method made use of audio and video in bringing different groups at different sites together for a class. The study indicated that students were aware of the benefits of this method. However, preference for face-to-face teaching was still favoured. The authors pointed out that this research confirmed the results of prior research undertaken by Seay and Milkman (1994) on the use of teleteaching where students at a remote site outperformed students at the original site (Seay and Milkman, 1994). In conclusion, this teaching method in university classes is still at the early stages of development and continuous research and development needs be undertaken to ensure its effectiveness.

\section{The offshore campus model for English as Second Language learners}

The introductory accounting course in a selected offshore campus aims to introduce students to the role of accounting and accounting information in business and also in society more broadly. In this course students are learning the basic principles underlying the production of financial information and its use in decision-making by various user groups. 
The model utilised an integrated approach in teaching the Introductory Accounting Course. It consisted of using the 'lecture and the tutorial model' and embedding English in the course. It also provided a focus on the support needed by students specific to Accounting particularly, providing special sessions on technical topics and highlighting financial interpretation and analysis. A programme was also initiated to manage at-risk students in the course.

The students who were taking Introductory Accounting in this offshore campus are divided into two streams, the first being 'Diploma' students who are taking two academic courses alongside the required advanced English language courses. One of the academic courses is Introductory Accounting. The second stream of students is the 'Direct Entry' group. These students have achieved the required English proficiency required for admission and take up to four academic courses each term. Each class consists of students coming from both streams. Students have English as a second language.

\section{The 'Lecture and Tutorial' Model}

The course is delivered in a lecture and tutorial format. All students are required to attend an hour and a half lecture per week in large classes and then a face-to-face tutorial session with 25 students in a class. The Diploma has two (2) sessions comprising an hour and a half tutorial per week while the Direct Entry has one session in the form of a two-hour per week tutorial class. The pacing of tutorial classes is slower in the Diploma stream. Diploma is given more opportunity to attempt practice exercises with the guidance of their lecturers.

\section{The use of lecture notes}

A typical lecture uses different types of visual aids including slides with minimal content, highlighting key words and also distributing clearly laid-out hand-outs. In addition, a 'Lecture Notes' template, which is a pro forma of a topic outline for every session is provided to students. Students are encouraged to take notes in the class. The Lecture Notes outline the highlighted key terms and these are emphasised in the tutorial supported by accompanying simple and practical illustrations.

Since the lectures are in large classes, students are encouraged to participate in simple step-by-step illustrations and group dynamics, such as pair work in attempting exercises. The course induction aims to ensure clarity and understanding of the course itself. Students are in their first year and are mostly new to the Australian system so it is imperative that time and effort is spent on providing a clear explanation of courserelated information, as well as an overview of the application of accounting in business and in their everyday lives. The aim is to clarify the changing role of accounting and the USER approach to avoid negative preconceptions or anxiety towards accounting. 


\section{Scaffolding technique and hands-on exercises}

The use of materials with varying levels of difficulty is placed in a database. Lecturers run the tutorials and are provided with lesson plans prior to the start of the term. Students' time is at least $70 \%$ hands-on in every tutorial class. Tutorials are in small groups of 25 and lecturers are able to follow every individual's performance and focus on each of their learning needs. The aim is to be able to provide individual attention to students.

In the tutorial, a 'scaffolding technique' is used. This technique according to Scrivener (1994) is a popular approach used in teaching language to learners whose mother tongue is not English. It refers to the way a teacher or someone competent in the English language assists one who has difficulty by encouraging and providing them with clues or guidance to assist them to create their own spoken structure. This method is being applied to ensure that the topics provide a step by step illustration and each topic is first introduced in the lecture. Then this will be followed with exercises in tutorials, starting from easy to a certain level of difficulty. At the onset, lecturers (tutors) provide guidance on how exercises should be attempted. As it progresses, students are able to do these exercises without any assistance.

\section{Student support initiatives (embedding English)}

The role of English to support second language learners is deemed important, especially for writing financial reports or conducting analysis, and in vocabulary building specific to the technical terms used. Examples of support in this area include:

\section{Ratio analysis workshop}

In the Ratio Analysis topic, students are required to hand-in a major assignment on financial ratios analysis. During the week of lecturing this topic, a workshop run by English lecturers of the university are offered on a separate session to students on a voluntary basis. The workshop is designed by both the Accounting staff and the English Department.

\section{Vocabulary guide}

A vocabulary guide is distributed as an "End of Chapter" review and this is used as part of tutorial classes relating to topics with rich vocabulary and that are heavy on technical terms.

\section{Lecturers' consultation time}

Each lecturer schedules a one and a half hour of consultation time for their tutorial group on a weekly basis. Students are encouraged to see their lecturers (tutors) for guidance. This one-on-one personal session aims to encourage students to feel comfortable with their lecturers to avoid anxiety in the course. 


\section{Learning support for at-risk students}

Lecturers take care to ensure that they are aware of at-risk students, especially those who are repeating the course following an initial failure. They are able to give extra attention and consultation as needed to improve the students' performance. A follow up program has been designed for the Student Advisement to work closely with the course lecturers. Students who are at risk are required to meet their tutorial lecturers with a course-specific form to monitor and record their performance and this is submitted to the Advisement section at certain intervals during the semester to report the student's progress.

\section{Accounting games and Accounting events}

In every term, an accounting event is organised to make the course fun. Enrolled students in Introductory Accounting are free to join in the Accounting games and events such as the Accounting Quiz as a group competition per class with prizes sponsored by top industry Accounting firms and other multinational companies. There are also events such as guessing games, and other exciting activities like raffles with accompanying prizes for the Introductory Accounting students usually held within the campus for other students to enjoy. These initiatives aim to promote a sense that Accounting is fun and exciting. When learning is interesting to students they experience deep learning (Abbott \& Palatnik, 2018). Similar studies also found that deep learning encouraged better teamwork, better student-faculty relationships, and teaching. All these have positive contributions to students' success in their future accounting courses (Abbott \& Palatnik, 2018; McBride, Hannon, \& Burns, 2005; Mladenovic, 2000; Turner \& Baskerville, 2013).

\section{Conclusion}

The Introductory Accounting course had previously reported a high failure rate among first year students. First year students perceived the course to be difficult. Students also found this course to be dull and boring. The integrated approach - using lecture and tutorial, embedding English and engaging students in the course - has had pivotal change in the perception of students towards the subject as well as contributing to a better outcome. That is, failure rates have improved.

The initiative presented in this paper is the end result of constantly improving the delivery of the course in an offshore campus since 2006. The implementation of the lecture and tutorial mode commenced in 2010 and has been constantly improved to enhance students' learning. From 2010 onwards, the offshore campus has had a consistent passing rate (averaging to 85\%) of 'Degree' students as compared to the main campus, with even a higher passing rate in some semesters. The figures can be seen in 
Table 1 presenting the failure rates from year 2010 - 2012. It should be noted that the pass rate of 'Diploma' students is not comparable to the students in the main campus as 'Diploma' students are a special cohort as they are taking two academic courses per term alongside English courses.

The paper highlights some innovative techniques in the teaching of the first accounting course. It has introduced the different ways the techniques can be used in particular setting. The techniques mentioned were derived from studies where students have English as their first language. Despite their relative strength in the English language, these students still find Introductory Accounting course a challenge.

The integrated model of teaching Introductory Accounting to English as second language learners was presented and discussed. This integrated model has emphasised the importance of student centred teaching focusing on engaging students in the learning process and particularly embedding English in the teaching of Introductory Accounting. A focus on simplifying the explanations of technical terms in Accounting and providing practical and relatable illustrations are highlighted in the course. Hands-on exercises are also implemented with the guidance of tutors or lecturers. To make the course fun and to change students negative pre-conception of the course, Accounting games and events have been introduced with major prizes and rewards from well-known companies. These events have been sponsored by big accounting firms. And lastly, those who are struggling in the course and are at-risks are given a range of support to catch up with the course. Over-all, it has been an effective model and is strongly recommended to Introductory Accounting students who have English as second language learners.

TABLE 1. Failure rates in Introductory Accounting course from year 2010 - 2012

\begin{tabular}{|c|c|c|c|c|c|c|c|c|}
\hline \multirow[b]{2}{*}{ Semester } & \multicolumn{7}{|c|}{ Failure Rates } & \multirow[b]{2}{*}{$\begin{array}{l}2012 \\
\text { Term C }\end{array}$} \\
\hline & $\begin{array}{c}2010 \\
\text { Term B }\end{array}$ & $\begin{array}{c}2010 \\
\text { Term C }\end{array}$ & $\begin{array}{c}2011 \\
\text { Term A }\end{array}$ & $\begin{array}{c}2011 \\
\text { Term B }\end{array}$ & $\begin{array}{c}2011 \\
\text { Term C }\end{array}$ & $\begin{array}{l}2012 \\
\text { Term A }\end{array}$ & $\begin{array}{l}2012 \\
\text { Term B }\end{array}$ & \\
\hline $\begin{array}{l}\text { Direct } \\
\text { Entry }\end{array}$ & $11 \%$ & $19 \%$ & $11 \%$ & $5 \%$ & $10 \%$ & $14 \%$ & $10 \%$ & $12 \%$ \\
\hline
\end{tabular}

The table above shows the failure rates from the year 2010 Semester B to Semester C 2012 for Direct Entry students.

Acknowledgement: Presented at FYHE International Conference 2013, July 7 - 10, Wellington, New Zealand by Mark Wheaton, Head of Department, Accountancy. The author would like to acknowledge the contribution of Brendan Smith (RMIT English Lecturer) 
Lego - Volume 2 - Issue 3-2020, p. 255-266.

\section{References}

Accounting Education Change Commission (AECC).(1990). Objectives of education for

accountants: Position Statement Nol. Issues in Accounting Education. (Fall). 307-312. Retrieved from http://aaahq.org/AECC/pdf/position/pos1.pdf

Accounting Education Change Commission (AECC).(1992).The First Course in Accounting:

Position Statement No.2. Issues in Accounting Education. (Fall). 330-331. Retrieved from http://aaahq.org/AECC/pdf/position/pos2.pdf

Albrecht, W.S., and Sack, R.J. (2000). Accounting Education: Charting the Course through a

Perilous Future. Accounting Education Series, Volume 16. Sarasota, FL: AAA.

Black, W. H. (2012). The activities of the pathways commission and the historical context for changes in accounting education. Issues in Accounting Education, 27(3), 601-625.

Bonner, P. (2012). Commission issues seven recommendations for bolstering the future of accounting education. Journal of Accountancy, 214(4), 38.

Camp, J. M., \& Schnader, A. L. (2010). Using debate to enhance critical thinking in the accounting classroom: The Sarbanes-Oxley Act and US tax policy. Issues in accounting education, 25(4), 655-675.

Diller-Haas, A. (2004). Time to change introductory accounting. The CPA Journal, 74(4), 60.

Dresnack, W.H. \& Callahan, C. III. (1998) The User Approach Versus the Traditional

Approach: A Comparison of the Effects of Introductory Accounting Course Work on Student Success in the Introductory Finance Course. Department of Business Administration and Economics. State University of New York College, Brockport.

Etter, E.R., Burmeister, S.L, \& Elder, R.J. (2000). Improving Student Performance and

Retention via Supplemental Instruction.Journal of Accounting Education, 18, 355-368. Doi: 10.1016/S0748-5751(01)00006-9

Halabi, A. K. (2005, June). Accounting tele teaching lectures: issues of interaction and performance. In Accounting Forum (Vol. 29, No. 2, pp. 207-217). Taylor \& Francis.

Jackling, B., \& De Lange, P. (2009). Do accounting graduates' skills meet the expectations of employers? A matter of convergence or divergence. Accounting Education: an international journal, 18(4-5), 369-385.

Kavanagh, M. H., \& Drennan, L. (2008). What skills and attributes does an accounting graduate need? Evidence from student perceptions and employer expectations. Accounting \& Finance, 48(2), 279-300.

Madsen, P. E. (2015). Has the quality of accounting education declined?. The Accounting Review, 90(3), 1115-1147.

Malgwi, C.A. (2004). Determinants of accounting anxiety in business students. Journal of

College Teaching and Learning, 1(2).81-94. 
McBride, H., Hannon, S., \& Burns, B. (2005). Developing critical thinking abilities in business and accounting graduates. Irish Accounting Review, 12(2).

Mladenovic, R. (2000). An investigation into ways of challenging introductory accounting students' negative perceptions of accounting. Accounting Education, 9(2), 135-155.

Pathways Commission. (2012). The Pathways Commission: Charting a national strategy for the next generation of accountants. Retrieved November, 1, 2012.

Scrivener, J. (1994). Learning Teaching. Macmillan Books for Teachers. Macmillan Education.

Spiceland, C. P., Spiceland, J. D., \& Schaeffer III, S. J. (2015). Using a course redesign to address retention and performance issues in introductory accounting. Journal of Accounting Education, 33(1), 50-68.

Turner, M., \& Baskerville, R. (2013). The experience of deep learning by accounting students. Accounting Education, 22(6), 582-604.

Turner, K. G., Lesseig, V. P., \& Fulmer Jr, J. G. (2006). Motivation in the first accounting course. The CPA Journal, 76(5), 66. 